\title{
EFFECTS OF CHLORINATED BENZENES ON THE ACTIVITIES OF $\delta$ - AMINOLEVULINIC ACID SYNTHETASE AND HEME OXYGENASE AND ON THE CONTENT OF HEMOPROTEIN IN THE LIVER OF RATS*
}

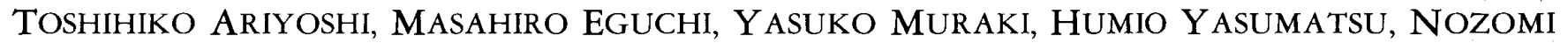 \\ SUETSUGU AND KOJI ARIZONO
}

Faculty of Pharmaceutical Sciences, Nagasaki University, 1-14 Bunkyo-machi, Nagasaki-shi, Nagasaki, 852, Japan

(Received July 16, 1980)

Effects of chlorinated benzenes on the activities of $\delta$-aminolevulinic acid ( $\delta$-ALA) synthetase and heme oxygenase, the rate-limiting enzyme in heme biosynthesis and degradation respectively, and on the incorporation of ${ }^{3} \mathrm{H}-\delta$-ALA into hemoprotein in the liver of male rats were investigated.

Monochlorobenzene(MCB) and 1,2,4-trichlorobenzene(TRCB) stimulated significantly the activities of above both hepatic enzymes.

After a single injection of $200 \mathrm{mg} / \mathrm{kg}$, heme oxygenase activity was enhanced rapidly and sustained markedly for at least $48 \mathrm{hr}$ by MCB treatment, while that was also enhanced but restored nearly to control levels at $48 \mathrm{hr}$ by TRCB. $\delta$-ALA synthetase activity was once decreased at $6 \mathrm{hr}$ and restored within $12 \mathrm{hr}$ and then reached peak levels (about 2-3 times to control levels) at $24 \mathrm{hr}$ by MCB or TRCB treatment. However, this activity was sustained for $48 \mathrm{hr}$ by TRCB treatment, whereas returned again to nearly control levels by MCB at $48 \mathrm{hr}$. Cytochrome P-450 content at $48 \mathrm{hr}$ was significantly decreased by MCB (63\% to control), in contrast, increased by TRCB (200\% to control).

When MCB or TRCB injected once daily throughout the study, biphasic disappearance of radioactivity incorporated into CO-binding particles was shown in control and MCB- or TRCB-treated rats. The half-life of the fast phase was about $8 \mathrm{hr}$ in control and about 6 or $13 \mathrm{hr}$ in MCB- or TRCB-treated rats respectively.

Keywords - monochlorobenzene; 1,2,4-trichlorobenzene; $\delta$-aminolevulinic acid synthetase; heme oxygenase; cytochrome P-450; incorporation of ${ }^{3} \mathrm{H}$ - $\delta$-aminolevulinic acid; CO-binding particles

Halogenated benzenes, which are used in the industry, agriculture, and even home, have been shown to influence the metabolism of foreign organic compounds. ${ }^{1-7)}$ The biochemical properties of hexachlorobenzene, in particular, has been extensively studied and identified to be a potent inducer of xenobiotic metabolism. ${ }^{2,7-9)}$ Our previous studies ${ }^{3-5}$ indicated that a number of chlorinated benzenes except monochlorobenzene also induce microsomal drug-metabolizing enzymes in the liver of rats in relatively higher doses used and shorter time periods, and that especially 1,2,4-trichlorobenzene is a most potent inducer among these compounds. Two compounds, monochlorobenzene(MCB) and 1,2,4trichlorobenzene(TRCB), were of particular interest because both chlorinated benzenes enhanced markedly $\delta$-aminolevulinic acid $(\delta$ ALA) synthetase activity, the initial and ratelimiting enzyme in porphyrin biosynthetic path-

Parts of this work were presented at the 96 th Meeting of Pharmaceutical Society of Japan, Nagoya, April 1976, and at the 100th Meeting, Tokyo, April 1980. 
way. Cytochrome P-450 content, however, was decreased by the treatment with MCB, whereas increased significantly by TRCB. Since induction of cytochrome $\mathrm{P}-450$ by various drugs and chemicals is associated with an increase in $\delta$-ALA synthetase activity, ${ }^{10-14)}$ the effect of MCB on cytochrome P-450 content might be due to the stimulation of heme degradation or to the inhibition of porphyrin utilization.

In this study, therefore, we have determined the activities of $\delta$-ALA synthetase and heme oxygenase which is the rate-limiting enzyme in heme degradation, and have made an attempt to clarify the relationship between cytochrome P450 content and the enzyme activities in heme metabolic pathway.

\section{METERIALS AND METHODS}

Chemicals - Monochlorobenzene (MCB) and 1,2,4-trichlorobenzene (TRCB) were obtained from Nakarai Chemicals Ltd., Kyoto, Japan. $\delta$-aminolevulinic acid( $\delta$-ALA) and hemin were purchased from Daiichi Pure Chemicals Co., Ltd., Tokyo and Tokyo Kasei Kogyo Co., Ltd., Tokyo, Japan, respectively. Nicotinamide adenine dinucleotide phosphate, glucose 6-phosphate disodium salt, and glucose 6-phosphate dehydrogenase were obtained from Boehringer Man- nheim Yamanouchi Co., Ltd., Tokyo, Japan. $\delta-\left[3,5-{ }^{3} \mathrm{H}(\mathrm{N})\right]-\mathrm{Aminolevulinic}$ acid hydrochloride $\left({ }^{3} \mathrm{H}-\delta\right.$-ALA, $5.05 \mathrm{Ci} / \mathrm{mmol}$, New England Nuclear Corporation) was purchased from Nippon Isotope Kyokai, Tokyo, Japan. Other chemicals of reagent grade were obtained from commercial sources and used without further purification.

Animals - Male rats of the Wistar strain weighing 110 to $130 \mathrm{~g}$ were used throughout the study. They were housed in an air-conditioned room with free access to food and water.

Assay Procedures - Chlorinated benzenes were dissolved in olive oil, and were injected intraperitoneally to animals. The control animals received the appropriate vehicle. For a doseresponse experiments, animals were injected with $\mathrm{MCB}$ at a single dose of 50,100 and $200 \mathrm{mg} / 2$ $\mathrm{ml} / \mathrm{kg} 24 \mathrm{hr}$ before sacrifice. The time course after treatment with $\mathrm{MCB}$ or TRCB at a single dose of $200 \mathrm{mg} / 2 \mathrm{ml} / \mathrm{kg}$ was examined by sacrificing animals at $6,12,24$ and $48 \mathrm{hr}$ following administration. For a incorporation of ${ }^{3} \mathrm{H}-\delta$-ALA into homoprotein, animals were treated with MCB or TRCB $(200 \mathrm{mg} / 2 \mathrm{ml} / \mathrm{kg}$ ) once daily for 3 days prior to the injection of ${ }^{3} \mathrm{H}-\delta$-ALA $(50 \mu \mathrm{Ci} / 2$ $\mathrm{ml} / \mathrm{kg}$ in $0.9 \% \mathrm{NaCl}$ ), and killed either 1 or $4 \mathrm{hr}$ after the isotope injection. For a disappearance of

TABLE I. Dose-Related Effect of MCB on the Activities of Hepatic $\delta$-ALA Synthetase and Heme Oxygenase and on the Content of Cytochrome P-450

\begin{tabular}{|c|c|c|c|}
\hline \multirow[t]{2}{*}{ Treatment } & \multicolumn{2}{|c|}{ Enzyme activity } & \multirow{2}{*}{$\begin{array}{c}\text { Content of } \\
\text { Cytochrome P-450 }\end{array}$} \\
\hline & $\delta$-ALA synthetase ${ }^{a}$ & Heme oxygenase $^{b)}$ & \\
\hline $\begin{array}{l}\text { Control } \\
\text { MCB }\end{array}$ & $35.0 \pm 1.1$ & $1.49 \pm 0.16$ & $1.04 \pm 0.08$ \\
\hline $50 \mathrm{mg} / \mathrm{kg}$, i.p. & $42.0 \pm 4.6$ & $4.38 \pm 0.24^{d)}$ & $1.00 \pm 0.13$ \\
\hline $100 \mathrm{mg} / \mathrm{kg}$, i.p. & $50.5 \pm 0.8^{d)}$ & $6.66 \pm 0.59^{e)}$ & $0.96 \pm 0.07$ \\
\hline $200 \mathrm{mg} / \mathrm{kg}$, i.p. & $73.2 \pm 4.0^{e)}$ & $12.93 \pm 0.89^{e)}$ & $0.73 \pm 0.04^{d)}$ \\
\hline
\end{tabular}

Animals were injected with monochlorobenzene (MCB) $24 \mathrm{hr}$ before sacrifice.

Each value represents the mean $\pm S$.E. of 4 rats.

a) $\mathrm{nmol} \delta-A L A / g$ liver/ $\mathrm{hr}$.

b) $\mathrm{nmol}$ bilirubin/ $\mathrm{mg}$ protein/ $\mathrm{hr}$.

c) $\mathrm{nmol} / \mathrm{mg}$ protein.

d) Significantly different from control, $p<0.05$.

e) Significantly different from control, $p<0.01$. 
labeled hemoprotein from CO-binding particles, animals treated with each chlorinated benzene $(200 \mathrm{mg} / 2 \mathrm{ml} / \mathrm{kg}$ ) once daily for 7 days, and on the 4th day were injected with ${ }^{3} \mathrm{H}-\delta$-ALA $(50$ $\mu \mathrm{Ci} / 2 \mathrm{ml} / \mathrm{kg}$ ) and killed at $6,12,24,48,72$ and 96 $\mathrm{hr}$ later. The rats were killed by decapitation, and the livers were perfused in situ with a cold $0.9 \%$ $\mathrm{NaCl}$ solution, and then homogenized with 3 volumes of $0.25 \mathrm{M}$ cucrose containing $\mathrm{lmM}$ EDTA in a Potter-Elvehjem homogenizer with a teflon pestle. Preparation of microsomes was carried out by procedures described previously. ${ }^{15)}$ Protein concentration was measured by the method of Lowry et al. ${ }^{16)}$ using bovin serum

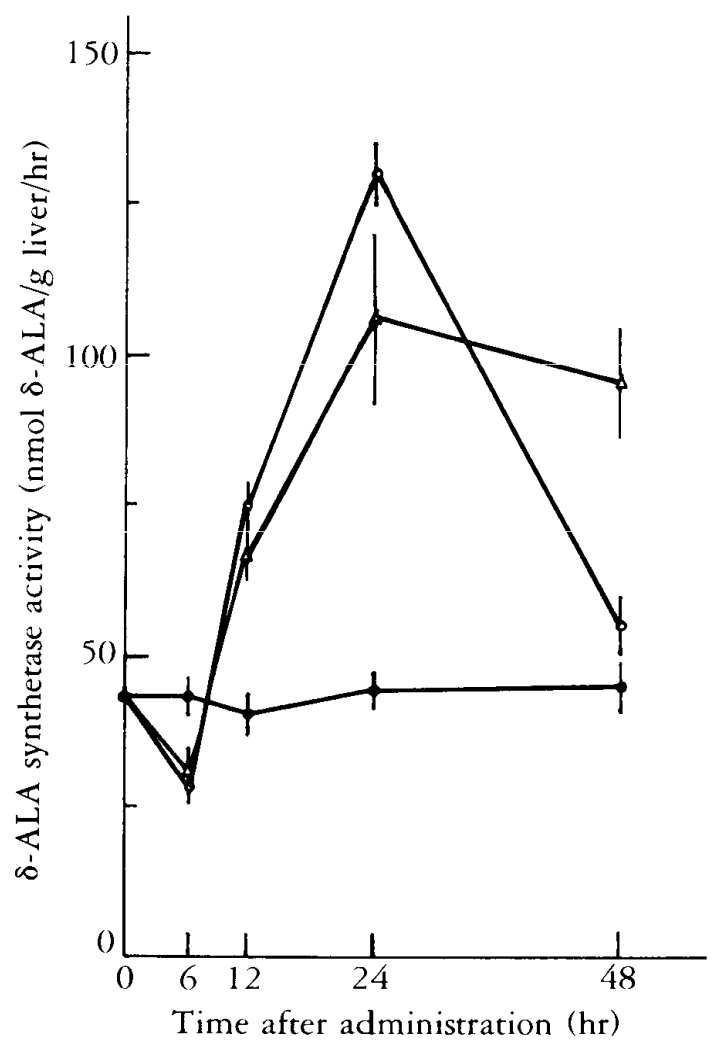

FIG. 1. Time Course of Induction of $\delta-A L A$ Synthetase Activity in the Liver from Rats Injected with $M C B$ or $T R C B$

Animals were injected intraperitoneally with $M C B$ or TRCB at single dose of $200 \mathrm{mg} / \mathrm{kg}$, and were killed at the indicated times after the administration. Each point represents the mean \pm S.E. of 4 rats.

$-\rightarrow$ control, $-\mathrm{O}-\mathrm{MCB},-\triangle-$ $T R C B$. albumin as standard. $\delta$-ALA synthetase activity of liver homogenates was determined by the method of Marver et al. ${ }^{17)}$ Heme oxygenase activity of microsomes was determined by the method of Maines and Kappas. ${ }^{18)}$ Cytochrome p-450 content was estimated as described by Omura and Sato. ${ }^{19)}$ The radioactivity incorporated into CObinding particles was measured by the method of Levin and Kuntzman. ${ }^{20)}$

\section{RESULTS}

As shown in Table I, MCB produced a roughly dose-related increase in activities of $\delta$-ALA synthetase and heme oxygenase in the liver of rats when measured $24 \mathrm{hr}$ after the administration. A single injection of MCB at a dose of $200 \mathrm{mg} / \mathrm{kg}$ caused the highest increase in activities of $\delta$-ALA

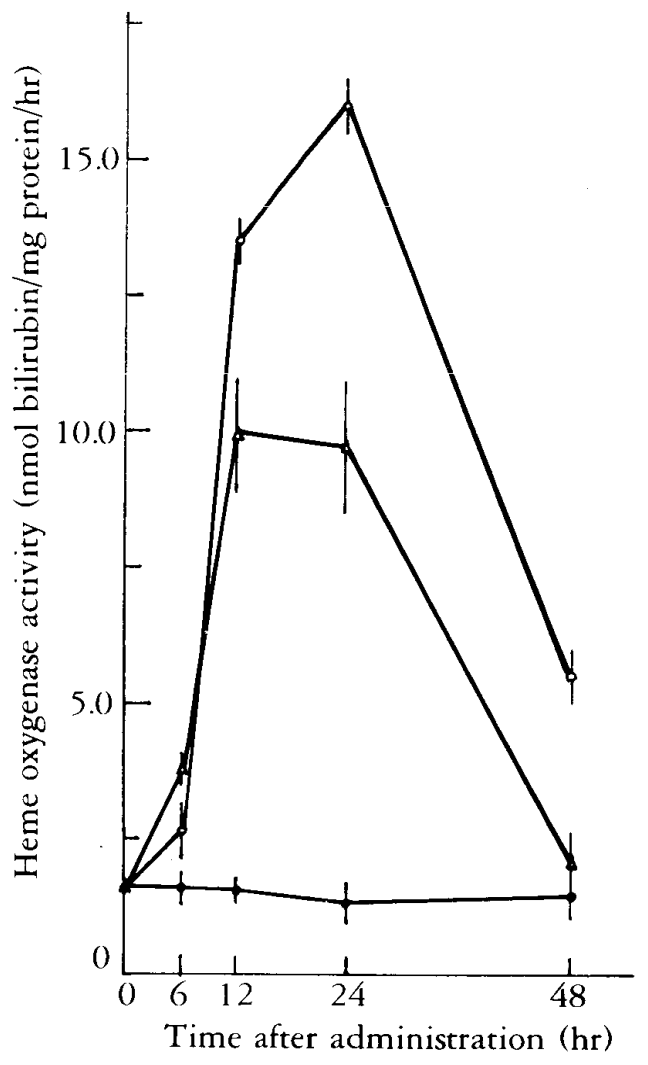

FIG. 2. Time Coutse of Elevation of Heme Oxygenase Activity in the Liver from Rats Injected with $M C B$ or $T R C B$

Conditions were as described in Fig. 1. Each point represents the mean $\pm S . E$. of 4 rats.

$T R C B$ 
synthetase and heme oxygenase, about 210 and $870 \%$ of control levels respectively, while the content of cytochrome P-450 was only $70 \%$ of control.

Figure 1 shows the time course of the effect of MCB or TRCB at a single dose of $200 \mathrm{mg} / \mathrm{kg}$ on hepatic $\delta$-ALA synthetase activity. This enzyme activity was decreased approximately $30 \%$ when measured $6 \mathrm{hr}$ after the administration, and subsequently restored and thereafter reached to peak values at $24 \mathrm{hr}$. This increased enzyme activity was again returned nearly to control levels $48 \mathrm{hr}$ after the administration of MCB, whereas the activity of TRCB continued to increase to about two-fold of the control levels at $48 \mathrm{hr}$.

Figure 2 shows the time course of induction of heme oxygenase after a single treatment at 200 $\mathrm{mg} / \mathrm{kg}$ with MCB or TRCB. A significant increase was observed $6 \mathrm{hr}$ after the injection of MCB or TRCB. This elevated enzyme activity continued for $24 \mathrm{hr}$ after the treatment with TRCB, and was sustained for $48 \mathrm{hr}$ after the administration of MCB.

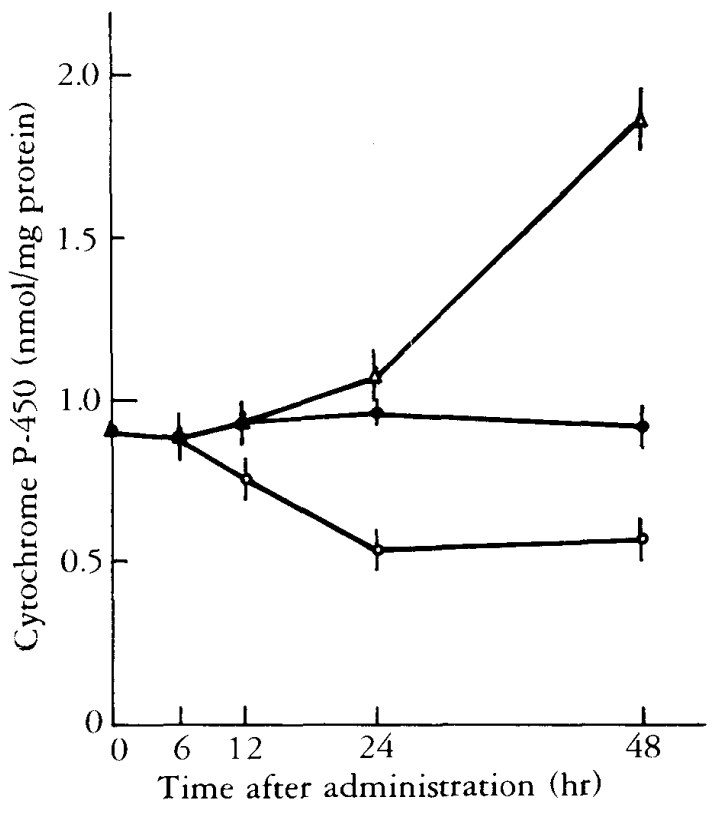

FIG. 3. Time Course of Loss and Induction of Cytochrome P-450 Content in the Liver from Rats injected with $M C B$ or TRCB

Conditions were as described in Fig. 1.

Each point represents the mean \pm S.E. of 4 rats.

- control, -O $\mathrm{MCB},-\triangle-$ $T R C B$.

TABLE II. Effect of $M C B$ or TRCB Treatment on Incorporation of ${ }^{3} H-\delta-A L A$ into $C O$-Binding Particles

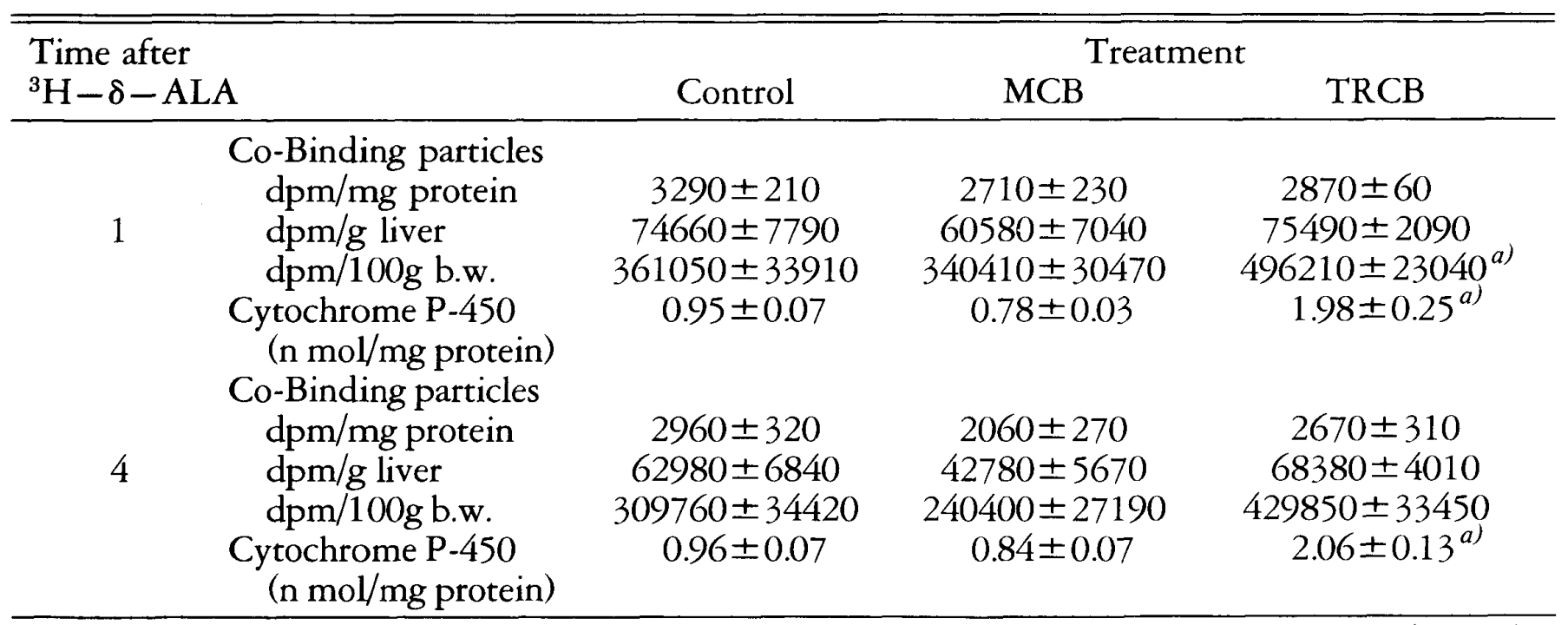

Animals were injected intraperitoneally with monochlorobenzene (MCB) or 1,2,4-trichlorobenzene (TRCB) at a single dose of $200 \mathrm{mg} / \mathrm{kg}$ once daily for 3 days.

On the 4th day, ${ }^{3} \mathrm{H}-\delta-A L A(50 \mu \mathrm{Ci} / \mathrm{kg})$ was injected intraperitoneally to rats, and the animals were killed either 1 or $4 \mathrm{hr}$ after the injection of the isotope.

Each value represents the mean \pm S.E. of 4 rats.

a) Significantly different from control, $p<0.05$. 
As shown in Figure 3, a remarkable decrease of cytochrome P-450 content was noted $24 \mathrm{hr}$ after the injection of MCB, and this significant depression was still noted at $48 \mathrm{hr}$. On the contrary, TRCB showed about two-fold increase of cytochrome P-450 content as compared to control levels at $48 \mathrm{hr}$.

Table II shows the incorporation of radioactivity into microsomal hemoprotein either 1 or $4 \mathrm{hr}$ after the injection of ${ }^{3} \mathrm{H}-\delta$-ALA $(50 \mu \mathrm{Ci} / \mathrm{kg})$. The radioactivity incorporated into the $\mathrm{CO}$-binding particles was observed to have a tendency to decrease by pretreatment with MCB (200 $\mathrm{mg} / \mathrm{kg} /$ day) for 3 days prior to the isotope injection, whereas the radioactivity per $100 \mathrm{~g}$ body weight after the treatment with TRCB increased $1 \mathrm{hr}$ after the isotope injection.

Figure 4 shows the results of disappearance of radioactivity with time from $\mathrm{CO}$-binding particles in control and chlorinated benzenes-treated rats. The data indicated a biphasic pattern of disappearance of radioactivity from the CO-binding particles obtained from both control and MCB- or TRCB-treated rats. A corrected half-life of the fast phase was about $8 \mathrm{hr}$ in control and approximately 6 or $13 \mathrm{hr}$ in MCB- or TRCB-treated animals respectively, as shown in inset of Figure 4. This corrected half-life of the fast phase was obtained by subtracting the radioactivity contributed by the slow phase after extraporating

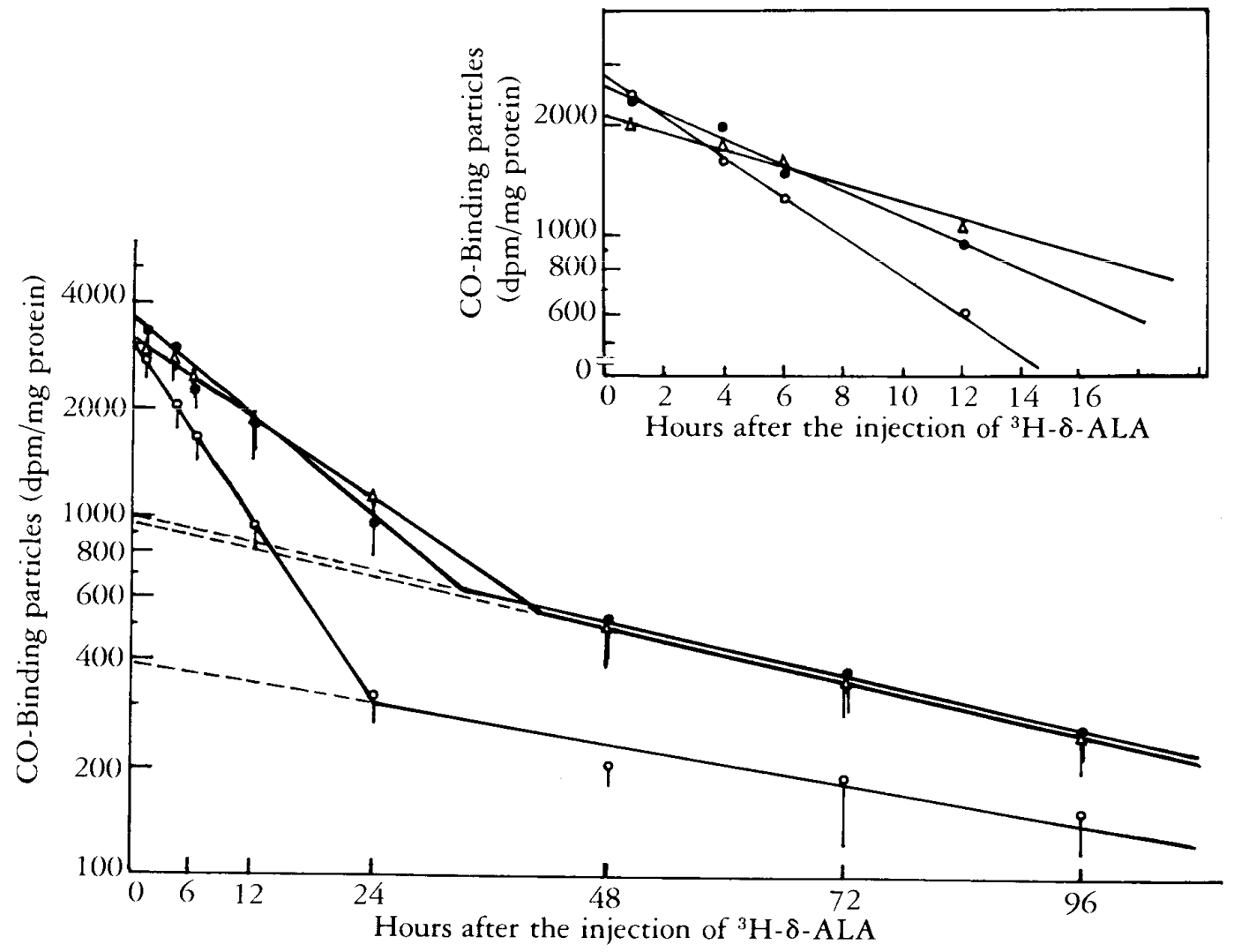

FIG. 4. Disappearance of Labeled Hemoprotein from CO-Binding Particles obtained from MCB- or TRCBTreated Rats

Animals were injected intraperitoneally with $M C B$ or $T R C B(200 \mathrm{mg} / \mathrm{kg} /$ day $)$ for 3 days prior to the injection of ${ }^{3} \mathrm{H}-\delta-A L A(50 \mu \mathrm{Ci} / \mathrm{kg})$, and were sacrificed at various times after the administration of the isotope. The injection of $M C B$ or TRCB continued every $24 \mathrm{hr}$ throughout the study. Each point represents the meant S.E. of 3 to 4 rats. Values used for the determination of the corrected half-life of the fast phase (inset) were obtained by first extraporating the slow phase to zero time and then subtracting the values of the extraporated slow phase from values of the uncorrected fast phase.

$-\mathrm{C}-\mathrm{control},-\mathrm{O}-\mathrm{MCB},-\triangle-T R C B$. 
back to zero times. The half-life of the slow phase hemoprotein was about $48 \mathrm{hr}$ in control or TRCB-treatd rats, but about $54 \mathrm{hr}$ in MCB-treated animals.

\section{DISCUSSION}

In the present study, we observed that MCB significantly decreased cytochrome P-450 content, but markedly enhanced the $\delta$-ALA synthetase activity. These findings agreed with our previous results ${ }^{3)}$ and further confirmed our earlier speculation on the ability of MCB which would accelerate the degradation of cytochrome P-450 heme, as well as lower the utilization of synthesized porphyrin. Therefore, we measured the heme oxygenase activity, the rate-limiting enzyme in heme degradation. This increase in enzyme activity was clearly dose-related after a single administration of $\mathrm{MCB}$, and the elevated activity was continued for at least $48 \mathrm{hr}$.

In addition, we found a relatively rapid disappearance of radioactivity in labeled hemoprotein from CO-binding particles as compared to control, namely about 8 or $6 \mathrm{hr}$ in corrected values of half-life at fast phase in control or MCB-treated rats, respectively. This half-life value in control rats coincided well with the value reported by Levin and Kuntzman. ${ }^{20)}$ Furthermore, pretreatment of rats with MCB for 3 days showed a tendency to depress the incorporation of ${ }^{3} \mathrm{H}-\delta$-ALA into hemoprotein either 1 or $4 \mathrm{hr}$ after the isotope injection. These findings suggest that MCB could induce a rapid degradation of heme or cytochrome P-450 heme, and furthermore it seems to inhibit, in part, the heme biosynthetic pathway somewhere.

On the other hand, a single injection of TRCB showed an increase of two-fold in $\delta$-ALA synthetase activity as compared to control even $48 \mathrm{hr}$ after the injection, whereas heme oxygenase activity at $48 \mathrm{hr}$ nearly restored to control levels. In the disappearance of labeled hemoprotein from $\mathrm{CO}$ binding particles, in addition, the half-life value at fast phase was about $13 \mathrm{hr}$ in TRCB-treated rats. These findings suggest that TRCB would con- tinuously increase hepatic heme synthesis through the prolonged induction of $\delta$-ALA synthetase, while it may not affect the decrease in cytochrome $\mathrm{P}-450$ heme because of rapid restoration of the heme oxygenase. Consequently, TRCB may lead to the increase in cytochrome P-450 content seen at $48 \mathrm{hr}$ after its administration. These different actions on the $\delta$-ALA synthetase or heme oxygenase and on the incorporation of ${ }^{3} \mathrm{H}-\delta$-ALA into hemoprotein or the values of half-life in labeled hemoprotein from CO-binding particles seems to have resulted in the overall difference on the cytochrome P- 450 content by the treatment with MCB or TRCB.

It was reported ${ }^{21-24)}$ that allylisopropylacetamide and other compounds containing allyl radical markedly increased the $\delta$-ALA synthetase activity, but these compounds decreased the cytochrome P-450 content at early phase after the injection, and that these results seemed to indicate a destruction of cytochrome $\mathrm{P}-450$ heme induced by active metabolites of the above compounds in vivo. Chemicals which promoted destruction of liver heme also may stimulate more effectively $\delta$ ALA synthetase, since heme is known to exercise a negative feed back control on the activity of porphyrin biosynthetic pathway at the level of $\delta$ ALA synthetase. Therefore, the regulation of $\delta$ ALA synthetase and of heme oxygenase in the liver are closely interrelated. In this study, we found the different effects on the $\delta$-ALA synthetase and heme oxygenase with time when administered MCB or TRCB to animals, and these might be caused by the difference in the formation of active metabolites in both chlorinated benzenes. Further investigation for metablism or for active metabolites of both chlorinated benzenes will be needed to clarify the relationship between cytochrome P-450 content and both enzyme activities.

Cobalt as well as other metals, such as iron, cadmium and lead, induced markedly heme oxygenase activity ${ }^{18,25-27)}$ in addition, both chlorinated benzenes also enhanced noteworthy enzyme activities as shown in this study. This 
appears to be toxicological problems, in consideration of the problem of contamination by chlorinated benzenes as one of the environmental pollutants, since these compounds remarkably affect both rate-limiting enzymes on the heme biosynthesis and degradation. Further study on a very low dose of chlorinated benzenes is being investigated.

\section{REFERENCES}

1) F.Oesch, D.M.Jarina, J.W.Daly and J.M.Rice: Induction, activation, and inhibition of epoxide hydrase: An anomalous prevention of chlorobenzene-induced hepatotoxicity by inhibitor of epoxide hydrase, Chem. Biol. Interact., 6, 189-202 (1973).

2) H.M.Mehendale, M.Fields and H.B.Matthews: Metabolism and effects of hexachlorobenzene on hepatic microsomal enzymes in the rats, J. Agr. Food Chem., 23, $261-265$ (1975).

3) T.Ariyoshi, K.Ideguchi, Y.Ishizuka, K.Iwasaki and M.Arakaki: Relationship between chemical structure and activity. I. Effects of the number of chlorine atoms in chlorinated benzenes on the components of drugmetabolizing system and the hepatic constituents, Chem. Pharm. Bull., 23, 817-823 (1975).

4) T.Ariyoshi, K.Ideguchi, K.Iwasaki and M.Arakaki: Relationship between chemical structure and activity. II. Influences of isomers in dichlorobenzene, trichlorobcnzene and tetrachlobenzene on the activities of drug-metabolizing enzymes, Chem. Pharm. Bull., 23, 824-830 (1975).

5) T.Ariyoshi, K.Ideguchi, K.Iwasaki and M.Arakaki: Relationship between chemical structure and activity. III. Dose-response or time-course of induction in microsomal enzymes following treatment with 1,2,4trichlorobenzene, Chem. Pharm. Bull., 23, 831-836 (1975).

6) G.P.Carlson and R.G.Tardiff: Effect of chlorinated benzenes on the metabolism of foreign organic compounds, Toxicol. Appl. Pharmacol., 36, 383-394 (1976).

7) G.P.Carlson: Induction of cytochrome P- 450 by halogenated benzenes, Biochem. Pharmacol., 27, 361-363 (1978)

8) M.D.Stonard and P.S.Nenov: Effect of hexachlorobenzene on hepatic microsomal enzymes in the rat, Biochem. Pharmacol., 23, 2175-2183 (1974).

9) J.C.Turner and R.S.Green: Effect of hexachlorobenzene on microsomal enzyme systems, Biochem. Pharmacol., 23, 2387-2390 (1974).

10) O.Wada, Y.Yano, G.Urata and K.Nakao: Behavior of hepatic microsomal cytochromes after treatment of mice with drugs known to disturb porphyrin metabo- lism in liver, Biochem. Pharmacol., 17, 595-603 (1968).

11) J.Baron and T.R.Tephly: The role of heme synthesis during the induction of hepatic microsomal cytochrome P-450 and drug metabolism produced by benzpyrene, Biochem. Biophys. Res. Commun., 36, 526-532 (1969).

12) A.Poland, J.Goldstein P.Hickman and V.W.Burse: A reciprocal relationship between the induction of $\delta$ aminolevulinic acid synthetase and drug metabolism produced by $m$-dichlorobenzene, Biochem. Pharmacol., 20, $1281-1290$ (1971).

13) F.De Matteis and A.Gibbs: Stimulation of liver 5aminolaevulinate synthetase by drugs and its relevance to drug-induced accumulation of cytochrome P-450: Studies with phenylbutazone and 3,5-diethoxycarbonyl-1,4-dihydrocollidine, Biochem. J., 126, $1149-1160$ (1972).

14) C.Rajamanickam, J.Amrutavalli, M.R.S.Rao and G.Padmanaban: Effect of hexachlorobenzene on haem synthesis, Biochem. J., 129, 381 - 387 (1972).

15) T.Ariyoshi, E.Takabatake and H.Remmer: Drug metabolism in ethanol induced fatty liver, Life Sci., 9, Part II, $361-369$ (1970).

16) O.H.Lowry, N.J.Rosebrough, A.L.Farr and R.J.Randall: Protein measurement with the Folin phenol reagent, $J$. Biol. Chem., 193, 265-275 (1951).

17) H.S.Marver, D.P.Tschudy, M.G.Perlroth and A.Collins: $\delta$-Aminolevulinic acid synthetase. I. Studies in liver homogenates, J. Biol. Chem., 241, 2803-2809 (1966).

18) M.D.Maines and A.Kappas: Studies on the mechanism of induction of haem oxygenase by cobalt and metal ions, Biochem. J., 154, 125-131 (1976).

19) T.Omura and R.Sato: The carbon monoxide-binding pigment of liver microsomes. I. Evidence for its hemoprotein nature, J. Biol. Chem ., 239, 2370-2378 (1964)

20) W.Levin and R.Kuntzman: Biphasic decrease of radioactive hemoprotein from liver microsomal CObinding particles, J. Biol. Chem., 244, 3671-3676 (1969).

21) U.A.Meyer and H.S.Marver: Chemically induced porphyria: Increased microsomal heme turnover after treatment with allylisopropylacetamide, Science, 171, 64-66 (1971).

22) W.Levin, E.Sernatinger, M.Jacobson and R.Kuntzman: Destruction of cytochrome P-450 by secobarbital and other barbiturates containing allyl groups, Science, 176, 1341 - 1343 (1972).

23) G.Abbritti and F.De Matteis: Decreased levels of cytochrome P-450 and catalase in hepatic porphyria caused by substituted acetamides and barbiturates: Importance of the allyl group in the molecule of the active drugs, Chem. -Biol. Interact., 4, 281-286 
$(1971 / 72)$

24) W.Levin, M.Jacobson, E.Sernatinger and R.Kuntzman: Breakdown of cytochrome P-450 heme by secobarbital and other allyl-containing barbiturates, Drug Metab. Dispos ., 1, 275-285 (1973).

25) F. De Matteis and A.H.Gibbs: Inhibition of haem synthesis caused by cobalt in rat liver: Evidence for two different sites of action, Biochem. $J ., 162,213-216$ (1977)
26) H.C.Kransny and D.J.Holbrook, Jr.: Effects of cadmium on heme oxygenase and hemoproteins in smooth and rough endoplasmic reticulum of rat liver, Biochem. Pharmacol., 27, 364-366 (1978).

27) N.G.Ibrahim, S.T.Hoffstein and M.L.Freedman: Induction of liver cell haem oxygenase in iron-overloaded rats, Biochem. J., 180, 257-263 (1979). 